\title{
PROPOSTA DO COMITÊ DE GEOFÍSICA PROFUNDA AO FÓRUM PARA O DESENVOLVIMENTO DE MÉTODOS PARA A EXPLORAÇÃO MINERAL NA AMAZÔNIA
}

\author{
Comitê Ad hoc Plataforma EXMIN/Amazônia
}

\begin{abstract}
Estão aqui apresentadas as análises, propostas, conclusões e recomendações do Comitê de Geofísica Profunda do Projeto Plataforma EXMIN/Amazônia, resultantes das discussões realizadas entre 24 e 26 de abril de 2000. Representam o consenso obtido por pesquisadores e especialistas em Geofísica, provindos de entidades do governo, empresas, universidades e centros de pesquisa, no que concerne a aplicação de técnicas e metodologias geofísicas para a identificação de estruturas geológicas profundas, eventos tectônicos e parâmetros físicos da litosfera, tendo em vista a exploração mineral e petrolífera na região amazônica.
\end{abstract}

\section{INTRODUÇÃO}

A percepção da importância das grandes unidades e estruturas da litosfera, determinadas com a geofísica profunda integrada com outros dados mais superficiais da geofísica de exploração, tem-se intensificado muito no âmbito da comunidade de pesquisa mineral e de hidrocarbonetos. A litosfera constitui o arcabouço para os grandes processos tectônicos que controlam e condicionam as características das províncias geológicas da crosta. O seu conhecimento é essencial não somente para uma melhor compreensão da evolução tectônica da crosta e dos limites de suas províncias como também para desvendar processos metamórficos, metassomáticos, de mineralização e de maturação dos depósitos de hidrocarbonetos, afetados por eventos de origem profunda.

O conhecimento geofísico da litosfera ainda é muito incipiente no Brasil e quase inexistente na Amazônia, o que configura uma posição extraordinariamente desvantajosa em relação a outros países de vocação mineral, e particularmente deficiente frente às necessidades dos planejamentos estratégicos de exploração dos recursos naturais do subsolo da região. $\mathrm{O}$ desconhecimento das condições litosféricas dificulta a seleção de áreas prioritárias para o direcionamento de estudos de maior detalhe. Esta situação retrata a inexistência de uma política de investimentos visando o conhecimento geofísico da crosta terrestre no Brasil por parte das entidades públicas responsáveis por tais ações.
Para reverter este quadro, especialistas das diversas áreas da geofísica profunda que atuam no Brasil no meio acadêmico e empresarial apresentam, neste relatório, uma proposta para subsidiar a exploração mineral na Amazônia. A proposta é coerente em seus aspectos científicos, em consonância com propostas de outras subáreas, particularmente as da Aerogeofísica e da Geotectônica - Metalogenia e engloba investigações como a sísmica, sismologia, gravimetria, magnetometria, indução eletromagnética e paleomagnetismo. As escolhas se fizeram por métodos e procedimentos de melhor custo/efetividade (benefício), considerando as dificuldades de trabalho na Amazônia. A meta deste esforço é mapear a geometria e as propriedades geofísicas dos grandes blocos litosféricos (numa escala de poucas centenas de $\mathrm{km}$ ) para posterior detalhamento. As sugestões apresentadas são viáveis para as atuais condições de aptidão e atuação da pesquisa nacional e disponibilidade de instrumentação. São também condicionadas pela expectativa realista de prováveis recursos para estes trabalhos, além da possível cooperação entre empresas, universidades e órgão públicos, e de um grande esforço na formação de capacitação especializada.

Uma sucessão de levantamentos, conduzidos de forma coordenada e com resoluções apropriadas para investigações em escalas litosféricas, será completada no prazo máximo de oito anos, de modo que os resultados possam ser divulgados e utilizados à medida em que forem sendo obtidos. O montante estimado para viabilizar 
esta proposta é de aproximadamente doze milhões de dólares, a serem liberados ao longo de oito anos e financiados por fontes distintas. A concentração dos gastos no período inicial decorre da relevância destas informações para o planejamento dos outros trabalhos de maior detalhe, como também do nível extremamente baixo de conhecimento da crosta profunda. Os projetos aqui propostos são indispensáveis para o programa geral do EXMIN/ Amazônia e para priorizar adequadamente a condução das investigações de menores profundidades a serem executadas por outros programas.

\section{REUNIÃO DO COMITÊ}

O Comitê de Geofísica Profunda do ProjetoPlataforma EXMIN/Amazônia reuniu-se no Torre Palace Hotel, em Brasília, entre 24 e 26 de abril para tratar da pauta geral abaixo especificada.

Participaram desta reunião os profissionais/ pesquisadores abaixo listados, oriundos de empresas associadas à ADIMB, de órgãos governamentais, institutos de pesquisa e universidades nacionais:

Antônio Lopes Padilha - INPE/MCT
Florivaldo Oliveira Sena-DOCEGEO
Ícaro Vitorello - INPE/MCT
João Willy Correa Rosa - UnB
Jurandyr Schmidt-PETROBRÁS
Lucas Vieira Barros - UnB
Luiz Augusto Bizzi - SOPEMI
Luiz Rijo- UFPA
Marcelo Sousa de Assumpção - IAG/USP
Márcia Ernesto-IAG/USP
Marco Aurélio Lemos Latgê-SBGf
Marta Silvia Maria Mantovani - IAG/USP
Renato Cordani - RTZ/Reconsult
Sérgio Luiz Fontes - ON/CNPq

Os debates realizados durante a reunião do Comitê, bem como as contribuições e sugestões enviadas por escrito, deram origem ao presente relatório, o qual foi preparado pelo grupo de redação composto por Ícaro Vitorello, Marcelo Assumpção e Luiz Bizzi, com a colaboração de Onildo João Marini e contribuições da Profa. Naomi Ussami (IAG/USP),
Prof. Augustinho Rigoti (UFPR), e Roberto G. de Souza Filho (ANGLOGOLD). O texto final foi submetido à aprovação de todos os membros do Comitê, após ter sido revisado.

\section{PAUTA DOS TRABALHOS}

As discussões abordaram os seguintes tópicos:

\section{Diagnóstico Técnico-Científico:}

1. Análise crítica da subárea de Geofísica Profunda no Brasil, aplicável a Amazônia, comparativamente a outros países mineiros, em especial Canadá, África do Sul e Austrália;

2. Identificação dos principais centros de pesquisa do país e exterior, suas capacitações, equipamentos, projetos principais em andamento na Amazônia, formação de recursos humanos e possíveis colaborações;

3. Identificação de deficiências em equipamentos, métodos e programas de computador existentes e eventuais necessidades de adaptação para aplicação na Amazônia.

\section{Propostas Para a Subárea:}

1. Sugestões de estudos e levantamentos básicos prioritários e meios para viabilizá-los;

2. Seleção de áreas e perfis a serem estudados;

3. Sugestões para integração dos comitês temáticos;

4. Proposição de política para geração e assimilação/adaptação de metodologias específicas para a Amazônia;

5. Proposição de programa induzido de formação clássica e continuada de pessoal.

\section{Viabilidade Técnica-Econômica:}

1. Sugestões de parcerias e possíveis fontes de recursos

2. Esboço de quantificação financeira. 
Priorização e Recomendações:

1. Seqüência de enfoques e ações prioritárias.

2. Recomendações outras que forem julgadas necessárias.

\section{DIAGNÓSTICO TÉCNICO-CIENTÍFICO}

\section{Análise Crítica Comparativa}

O conhecimento atual das características da crosta e litosfera Amazônica restringe-se a mapas em escalas continentais dos parâmetros físicos obtidos a partir de dados gravimétricos, magnetométricos e geotérmicos. Para a Amazônia, estes mapas representam informações que foram extrapoladas ou derivadas de maneira indireta. Propriedades físicas, estruturas e composição da litosfera abaixo da América do Sul têm sido inferidas a partir de dados gravimétricos e magnéticos regionais, compilados em diversos projetos internacionais (South American Gravity Project-SAGP; Anglo-Brazilian Gravity Project-ABGP; South American Magnetic Mapping Project-SAMMP) e através de esforços de grupos nacionais para a confecção de mapas com estimativas da espessura elástica efetiva, anomalias do geóide e de fluxo geotérmico, e obtenção de informações restritas de sismologia, paleomagnetismo e indução eletromagnética.

O conhecimento da crosta, principalmente o associado à morfologia do embasamento de bacias sedimentares, tem recebido maior atenção pelo interesse na exploração de petróleo, como nas bacias de Solimões e Amazonas, investigadas através de levantamentos terrestres de sísmica e modelagens por métodos potenciais, e as bacias do Alto Xingú e Alto Tapajós, recobertas por aerogravimetria e aeromagnetometria.

Informações sobre a sismicidade da Amazônia têm sido obtidas de maneira fragmentada por pesquisadores da UnB, através de estações sismográficas permanentes e móveis, localizadas principalmente em áreas de reservatórios. O IAG/USP realizou esforços para diminuir a carência de dados paleomagnéticos na Amazônia, em colaboração com pesquisadores da Finlândia. Nota-se também a inexistência no Brasil de levantamentos sistemáticos de parâmetros geofísicos (magnéticos, elétricos, radioativos, térmicos, porosidade, permeabilidade) de rochas e minerais, que são importantes para subsidiar as interpretações dos métodos geofísicos.

A grande carência de informações geofísicas sobre a natureza e estruturas da crosta e do manto litosférico na Amazônia contrasta fragrantemente com o grau de conhecimento que existe em outras regiões similares de escudos antigos do Planeta, como na Rússia (Sibéria), Canadá, África do Sul e Austrália. Em relação aos levantamentos de campos potenciais e sísmica, estes países têm seus territórios recobertos por dados coletados com espaçamentos em torno de $10 \mathrm{~km}$ para interpretações regionais e de $4 \mathrm{~km}$ em províncias minerais. Nesses países, as estruturas profundas maiores da crosta já foram devidamente delimitadas, graças à existência, principalmente, de vários milhares de quilômetros de linhas sísmicas profundas, de uma densa rede de estações gravimétricas e de milhares de sondagens de indução eletromagnética. Estes trabalhos foram executados através de recursos públicos assegurados por políticas de longo prazo. Em sismologia e indução eletromagnética, estes países apresentam estações localizadas entre 100 e $200 \mathrm{~km}$ para estudos regionais, e espaçamentos menores em áreas de interesse econômico.

Por exemplo, o cráton do Kaapval no sul da África foi estudado recentemente com estações sismográficas espaçadas a cada $100 \mathrm{~km}$ para mapeamento detalhado da crosta profunda e manto superior.. O exemplo clássico de fomento público direcionado a levantamentos geofísicos para a exploração mineral é o Projeto Lithoprobe de investigação profunda de diversas províncias minerais do Canadá, envolvendo estudos sísmicos, gravimétricos e de indução eletromagnética. Atualmente, extensos programas estão sendo elaborados na América do Norte (US-Array; Canadian Upper Mantle Imaging Consortium) e Europa (programa BEAR/EUROPROBE) para permitir o mapeamento 3-D da litosfera, com uma resolução muito superior ao atual.

$\mathrm{Na}$ Amazônia, existem apenas duas linhas sísmicas de reflexão profunda, no total de 150 quilômetros de extensão, ambas em áreas de bacias sedimentares e não existe rede gravimétrica, mesmo 
aberta. Os levantamentos gravimétricos existentes limitam-se a malhas muito locais, também em áreas de bacias sedimentares.

Por outro lado, a evolução tecnológica ocorrida nas últimas décadas resultou no desenvolvimento de equipamentos e de novos métodos de processamento de dados de geofísica, mais adequados, rápidos e econômicos. Destes, a gravimetria aerotransportada é de especial importância para a Amazônia, seja pela sua rapidez, seu baixo custo relativo e, principalmente, por permitir a obtenção homogênea de dados através de plataformas aéreas, sem a necessidade de enfrentar as dificuldades de locomoção na floresta. Esta nova metodologia, somada a controles terrestres pelos demais métodos em linhas ao longo de estradas e rios navegáveis, permitirá ao Brasil, num curto prazo, diminuir significativamente o atraso de conhecimento das estruturas profundas da Amazônia, relativamente a regiões similares de outros países.

A enorme defasagem no conhecimento sobre geofísica profunda existente no Brasil, como um todo, e na Amazônia em particular, relativamente a todos os demais países de grande porte do Planeta, devese, principalmente, ao fato do Serviço Geológico do Brasil - SGB (CPRM), contrariamente a todos os demais serviços geológicos, ter negligenciado sua capacitação e atuação em geofísica profunda. Como resultado, não existe um grupo de pesquisadores especializados em geofísica profunda no SGB. Em outros países, a grande maioria dos grandes projetos de geofísica tem sido liderados ou, no mínimo, tem tido a parceria dos serviços geológicos.

\section{Viabilidade Técnica}

A comunidade de geofísicos no Brasil é essencialmente composta por profissionais que atuam em métodos geofísicos exploratórios ou de âmbito regional, junto a empresas e universidades. Entretanto, uma pequena parcela de pesquisadores da área acadêmica tem atuado em levantamentos geofísicos profundos, geralmente em cooperação com entidades do exterior. Estas condições decorrem da carência de fomento a estes estudos e da falta de interesse demonstrado por entidades públicas na condução de trabalhos de geofísica profunda. A proposta apresentada leva em consideração a atual capacitação científica nacional, o que justifica o esforço em programas de formação de profissionais especializados e a contratação de empresas especializadas do exterior para os levantamentos, processamentos e mesmo interpretações dos dados coletados. Com a presente proposta, espera-se facilitar a formação de núcleos de trabalho nos centros de pesquisa com demonstrada experiência nos últimos ano, como também o desenvolvimento de novos grupos, principalmente dentro das organizações governamentais com responsabilidades de ações públicas na Amazônia e centros acadêmicos localizados na Amazônia.

Na subárea de Campos Potenciais, o principal centro de investigações profundas encontra-se no IAG/ USP, porém diversos outros grupos têm trabalhos voltados à geofísica regional e de exploração como a PETROBRAS, CPRM, UFPA, UFC, UFRN, UFPR, UFBA, e ON/MCT. Essas entidades possuem um número razoável de gravímetros e magnetômetros para uso em determinações terrestres. Sistemas aerotransportados podem ser contratadas de empresas especializadas.

A PETROBRAS é a única entidade que tem utilizado dados de perfilagem sísmica de reflexão para interpretações em regiões sedimentares da Amazônia, porém só com um trabalho desenvolvido no cráton Amazônico (Tese de PhD, em Cornell, de R. M. D. Matos). Os serviços de perfilagens são contratados de empresas do exterior. Processamentos e interpretações podem ser realizadas através de cooperação com entidades do exterior como por exemplo a University of Cornell (Larry Brown) e Univ. of South Carolina (James Knapp; Carmelia Diaconescu). Estudos sismológicos têm sido efetuados na Amazônia por equipes da UnB, em estações localizadas principalmente próximas a represas. Equipamentos para serem utilizados nesses trabalhos podem ser obtidos em convênios com entidades externas, como o Carnegie Institution of Washington (John VanDecar, David James), Virginia Tech (Arthur Snoke), Columbia University, Doherty Geol. Observatory.

Os principais grupos que atualmente efetuam levantamentos de indução eletromagnética em profundidades litosféricas são o INPE e ON, que contam com técnicos devidamente treinados e com 
diversas unidades de sondagens apropriadas para estudos profundos e programas de processamento de dados. Existe cooperação do ON e INPE com a UFPR e UFPA e entidades externas (Geological Survey of Canada; (Alan Jones) Flinders University (François Chammalaun), e Indian Inst. of Geomagnetism (B. R. Arora).

Para os trabalhos de paleomagnetismo, a USP conta com laboratórios e técnicos especializados na determinação dos diversos parâmetros paleomagnéticos e tem atuado na Amazônia em colaboração com pesquisadores da Finlândia.

\section{Viabilidade Econômica}

A interrupção do programa PADCT-III e a indefinição sobre os recursos governamentais do Fundo para o Desenvolvimento Técnico-Científico em Mineração limita a viabilização do programa de geofísica profunda aos recursos principalmente da ANP e MME/CPRM. Um montante ao redor de 50$60 \%$ do total estimado poderá ser financiado pela ANP, por se tratar de levantamentos geofísicos sobre bacias sedimentares. Para os levantamentos nas áreas cratônicas esperam-se recursos na ordem de 25-35\% oriundos da MME/CPRM e empresas de mineração. O restante dos recursos de 15-25\% do total, deverão ser obtidos das fundações estaduais de amparo às ciências e do MCT/CNPq. Outro problema decorre do fato que é necessário alocar $60 \%$ dos recursos para o primeiro ano do programa. Nos três anos seguintes são programados $10 \%$ do total por ano e nos últimos quatro anos $2,5 \%$ por ano.

\section{Capacitação e Atuação dos Principais Centros de Pesquisa em Geofísica Profunda.}

A capacitação nacional em geofisica profunda encontra-se principalmente nas universidades, muitas vezes com atuação em colaboração com centros de pesquisa do exterior.

Estudos de geofísica profunda na Amazônia têm sido esporádicos, sendo que mesmo nestes casos as informações são constituídas por mapas regionais com baixa densidade de dados reais e são produzidos por extrapolação, interpolação ou por métodos indiretos.
Abaixo são apresentadas as informações sumárias das capacitações de instituições públicas acadêmicas ou não, e de empresas nacionais em geofísica profunda, por metodologia. A lista, porém, nãoé exaustiva, havendo outros grupos e profissionais que deveriam complementar o quadro abaixo.

\section{Área Acadêmica:}

\section{IAG/USP}

\section{Sismologia \& Sísmica}

Pesquisadores: Marcelo Assumpção e Jesús Berrocal;

Atuação: sismicidade, estrutura da crosta e manto superior (não atuam na Amazônia atualmente)

Equipamentos: 10 estações de banda-larga, atualmente operando no SE e Centro-Oeste do Brasil, para estudos da crosta e manto Superior; Cooperação: Carnegie Institution of Washington, Virginia Tech, e US Geological Survey (Menlo Park), USA; ETH, Suiça.

\section{Gravimetria:}

Pesquisadores: Marta S. M. Mantovani, Naomi Ussami, Wladimir Shukowsky; Eder Cassola Molina, Yara R. Marangoni.

Atuação: Levantamentos e modelagem de dados gravimétricos das bordas do Cráton Amazônico; Mapas gravimétricos através da integração de diferentes tipos de dados geopotenciais; Flexura e espessura elástica da litosfera; Mapas de anomalias do geóide.

Equipamentos: 01 estação portátil de maré; 2 Gravímetros Lacoste \& Romberg modelo G, receptores GPS, levantamentos altimétricos por barometria e geométricos. Recursos computacionais como estações de trabalho em rede com microcomputadores e periféricos gráficos.

\section{Paleomagnetismo}

Pesquisadores: Marcia Ernesto, Igor I. G. Pacca Atuação: Deriva continental, modelos tectônicos, direções de magnetização, definição de unidades litosféricas, magnetismo de rochas. 
Equipamentos: quatro desmagnetizadores por campos alternados e térmicos, magnetômetros, medidores de susceptibilidade e anisotropia.

\section{INPE/MCT}

\section{Indução Eletromagnética}

Pesquisadores: A. L. Padilha; İcaro Vitorello

Atuação: Sondagens Magnetotelúricas em VilhenaPorto Velho; Sondagens geomagnéticas profundas na Bacia de Parnaíba. Estudos do Eletrojato Equatorial; Formação de recursos humanos: Dois doutores e dois mestres em Métodos Magnetotelúricos.

Equipamentos: Seis sistemas MT de período longo (>100 s); Dois sistemas MT banda larga (0,001$1,000 \mathrm{~s}$ ); Programas de processamento de dados MT e GDS

Recursos computacionais com micros e estações de trabalho.

Cooperação: Geological Survey of Canadá-GSC; Flinders University, Australia; Indian Institute of Geomagnetism.

\section{ON/CNPq}

\section{Indução Eletromagnética}

Pesquisadores : Sérgio Luiz Fontes; I. Figueiredo

Atuação: Sondagens Magnetotelúricas na Bacia do Parnaíba, Sondagens Magnetotelúricas na Bacia de Parecis;

Equipamentos: Quatro sistemas MT de período longo Dois sistemas MT de banda larga, Recursos computacionais e de laboratório.

Cooperação: University of Leeds; Geological Survey of Canada.

\section{UnB}

\section{Sismologia \& Sísmica}

Depto. de Geologia Geral

Pesquisadores: João Willy Correa Rosa

Atuação: instalação de duas estações permanentes na Amazônia; estudos de estrutura da litosfera com ondas de superfície e função do receptor; estrutura crustal no perfil Manaus - Pitinga com 4 estações
Equipamentos: 7 estações sismográficas portáteis (sensor Guralp + registradores RefTek)

Cooperação: Univ. Potsdam, Alemanha; Univ. de NY, USA.

\section{Observatório Sismológico}

Pesquisador: Lucas Vieira de Barros

Atuação: sismicidade natural e induzida na Amazônia; instalação de estações permanentes na Amazônia.

Equipamentos: 7 estações sismográficas permanentes (sensor Guralp + registradores Quanterra)

Cooperação: Eletronorte;

\section{UFBA}

\section{Sísmica de reflexão:}

Pesquisadores: Milton J Porsani, Reynam Pestana, Marco A B Botelho, Amin Bassrei, Wilson M Fiqueiro;

Atuação: migração, modelagem, inversão, supressão de reflexões múltiplas, deconvolução, estimativa do pulso sísmico, tomografia sísmica;

Equipamentos: estações de trabalho e computadorespessoais, algorítimos comerciais de processamento sísmico;

Cooperação: PETROBRAS, ANP, Petroleum Geoservice, University of Austin, The Norwegian University of Science and Technology.

\section{Gravimetria}

Pesquisadores: Edson E S Sampaio

Atuação: levantamentos regionais por métodos potenciais

Equipamentos: magnetômetros e gravímetros, suporte computacional.

Cooperação: PETROBRAS, ANP

\section{UFC}

\section{Campos potenciais}

Pesquisadores: R Mariano G Castelo Branco; David L de Castro

Atuação: levantamentos regionais, estruturas quimberlíticas

Equipamentos: gravímetros, magnetômetros, suporte computacional. 
UFPA

\section{Indução Eletromagnética}

Pesquisadores: Luiz Rijo, Om P. Verma, José Gouvêa Luiz, Cícero Régis

Atuação: Modelagem numérica e inversão de dados eletromagnéticos; Processamento e interpretação de dados magnetotelúricos; Efeitos do Eletrojato Equatorial nos dados magnetotelúricos.

Equipamentos: eGs 2000 (electrical Geophysics suite), conjunto de Programas para modelagem e inversão de dados Eletromagnéticos. Rede de estações de trabalho; Formação de recursos humanos: três teses de doutorado e quatro dissertações de mestrado relacionadas ao método MT.

Cooperação: GTZ, ON, INPE.

\section{Gravimetria}

Pesquisadores: João Batista Correia da Silva

Atuação: Processamento e interpretação de Dados Gravimétricos.

Equipamentos: Programas para interpretação de dados gravimétricos; Formação de recursos humanos: Três teses de doutorado e quatro Dissertações de mestrado relacionadas a interpretações de dados Gravimétricos;

\section{Sísmica}

Pesquisadores: João Carlos Cruz, Lourenildo B Leite, Jessé Carvalho, João dos Santos Protázio;

Atuação: Processamento e tomografia de dados sísmicos; Formação de recursos humanos: quatro teses de doutorado em Processamento e imageamento sísmico.

Equipamentos: estações de trabalho e computadores pessoais; programas Processamento sísmico (Focus/2D-Pardigm)

Cooperação: GTZ, DFG, Univ. de Karlsrule, Univ. de Stanford, UNICAMP, PETROBRAS;

\section{UFPR}

\section{Indução Eletromagnética}

Pesquisadores: Augustinho Rigoti
Atuação: Sondagens geomagnéticas profundas na Bacia do Parnaíba; Estudos do Eletrojato Equatorial;

Equipamentos: Programas de processamento de dados GDS

Cooperação: Flinders University (Australia)

\section{Gravimetria}

Pesquisadores: Sílvio Rogério Correia de Freitas e Carlos Aurélio Nadal

Atuação: Adensamento da Rede Gravimétrica no Estado do Paraná Determinações do Geóide.

Equipamentos: 2 Gravímetros Lacoste \& Romberg e 1 CG3 Scintrex 2 Conjuntos de posicionamento DGPS

\section{Magnetometria}

Pesquisadores: Augustinho Rigoti e Francisco José Fonseca Ferreira

Atuação: Processamento/Modelagens de dados aeromagnéticos; Levantamentos magnetométricos de superfície.

Equipamentos: 2 magnetômetros de campo total EnviMag Scintrex

Software Geosoft completo, última versão.

\section{UFRN}

\section{Gravimetria}

Pesquisadores: Walter Medeiros

Atuação: métodos de inversão geofísica, levantamentos regionais,

Equipamentos: gravímetros LaCoste-Romberg

Cooperação: UFPA, IAG/USP

\section{Área Governamental:}

\section{Serviço Geológico do Brasil (SGB)}

\section{Aeromagnetometria}

Contrariamente ao que ocorre em outros países, nos quais os serviços geológicos nacionais se constituem nas instituições líderes nos estudos de geofísica profunda, a CPRM não tem especialistas e não tem atuado nesta subárea vital para o 
conhecimento das grandes compartimentações tectônicas e estruturais da crosta e manto, nem mesmo através da terceirização de serviços.

$O$ único produto útil gerado indiretamente pela CPRM, embora secundário, para o estudo de geofísica profunda são os levantamentos de aeromagnetometria.

É fundamental, no interesse da exploração mineral e petrolífera, que o Serviço Geológico do Brasil envolva-se ou mesmo lidere urgentemente um programa integrado e abrangente, capaz de detectar as estruturas profundas controladoras dos depósitos minerais/petrolíferos na Amazônia.

\section{Agência Nacional do Petróleo - ANP}

\section{Sísmica e Gravimetria}

A recém criada ANP realiza, através da terceirização, estudos de geofísica profunda limitados às áreas de bacias sedimentares. Os métodos utilizados são, via de regra, sísmica de reflexão e gravimetria terrestre ou marinha, com destaque para o primeiro. A sísmica de reflexão, embora caríssima, fornece dados de grande resolução, sendo por esta razão instrumento de exploração petrolífera de grande sucesso.

\section{Aerogravimetria}

Levantamentos aerogravimétricos, hoje de posse da ANP, foram realizados pela PETROBRÁS nas regiões de bacias do Alto Xingu e Alto Tapajós e deverão ser usados em outras áreas da Amazônia. Estes são de rápida e fácil execução e fornecem valiosas informações para interpretar a estruturação profunda da crosta.

\section{Aeromagnetometria}

Os levantamentos regionais de aerogeofísica realizados pela PETROBRÁS pertencem hoje à ANP, que está estudando a elaboração de um programa de grande porte de aeromagnetometria nas bacias do Solimões e Amazonas.

\section{Área Empresarial}

\section{PETROBRÁS}

A PETROBRÁS é a única companhia nacional com fins lucrativos que investe em estudos de geofísica profunda, limitados evidentemente às bacias sedimentares.

\section{Sísmica}

A sísmica, principalmente de reflexão, constituise na metodologia mais amplamente empregado pela PETROBRÁS, em especial na Plataforma Continental (off shore) onde é usada intensamente.

\section{Gravimetria e Magnetometria}

Secundariamente, a PETROBRÁS realiza estudos de gravimetria, tanto terrestre como aérea, e de aeromagnetometria.

Todo o enorme acervo de geofísica profunda gerado pela PETROBRÁS em áreas de campos petrolíferos são de uso exclusivo da empresa.

\section{Outras Empresas}

\section{Aerogeofísica: $M A G$ e GAMA}

A capacitação e atuação de empresas privadas nacionais (exceto PETROBRÁS) em geofísica profunda, limita-se à área de obtenção de dados, essencialmente de aerogeofísica. Neste particular, graças a acordos e convênios internacionais, existem no Brasil algumas poucas empresas altamente capacitadas e operando no estado-da-arte internacional.

Todos os levantamentos de aerogeofísica realizados no País, nas duas últimas décadas, foram realizados por empresas particulares, trabalhando sob contrato para o DNPM, CPRM, PETROBRÁS, CNEN/NUCLEBRÁS, etc., ou para empresas de exploração mineral. As empresas prestadoras de serviços de aerogeofísica que operam no Brasil estão plenamente capacitadas a realizar, no mais alto nível internacional, levantamentos de aerogravimetria e 
aeromagnetometria, utilizáveis, em especial o primeiro, para interpretações de estruturas profundas.

\section{CONCLUSÕES}

O conhecimento dos grandes domínios litosféricos da Amazônia é praticamente nulo devido a falta de esforços conjugados para investigações profundas. Os estudos existentes são fragmentados e ainda muito incipientes para a definição adequada das grandes estruturas crustais e do manto litosférico. As poucas informações advêm da área acadêmica e de empresas, sendo que destas últimas, as informações têm sido muito pouco divulgadas fora do âmbito das empresas que as detém.

Em termos comparativos com outras regiões continentais, o conhecimento das características profundas pode ser caracterizado como inexistente na Amazônia, principalmente pelo fato dos dados serem descontínuos e de baixa densidade, fornecendo informações inadequadas.

Não tem havido no Brasil qualquer esforço ou experiência de trabalho conduzido de forma cooperativa na área da geofísica profunda ou envolvendo diversas áreas de pesquisa, a exemplo de outros países que têm adotado abordagens multidisciplinares e multi-institucionais. A atuação de grupos de pesquisa na região tem sido muito insignificante, devido aos problemas de acesso a região e à carência de financiamentos públicos e privados. Os raros estudos existentes são pontuais e foram efetuados por grupos acadêmicos ou por algumas empresas para testes operacionais.

As instituições governamentais, contrariamente ao que ocorre em outros países de elevado potencial mineral, têm demonstrado pouco empenho e os recursos para a realização de levantamentos e processamento de dados têm sido insignificantes nas áreas cratônicas.

A capacidade atual de pessoal e de equipamentos é limitada e inadequada para a realização de todos os extensos levantamentos que seriam desejáveis e necessários a curto prazo para o devido conhecimento da Amazônia.

Apesar de limitada, a capacitação nacional de recursos humanos, caso venha a receber os recursos aqui solicitados, tem condições, em conjunto com colaboradores do exterior, para realizar os projetos de pesquisa aqui propostos. Existe capacidade científica na área acadêmica nacional, nos vários tópicos da geofísica profunda, à altura para estabelecer o planejamento, a verificação da qualidade dos resultados e o processamento e interpretação dos dados. Algumas empresas particulares têm feito aquisição e processamento de dados que não têm se tornado públicos. $\mathrm{Na}$ área governamental, não existem capacidade, instrumentação e política pública de levantamentos e processamentos de dados direcionados ao reconhecimento da litosfera.

\section{RECOMENDAÇÕES}

Para promover o conhecimento geofísico em profundidades litosféricas são recomendados levantamentos conjugados e apropriados para a obtenção de informações sobre os parâmetros físicos e estruturas que ocorrem nestas profundidades, através de um esforço nacional envolvendo governo, empresas e universidades. A interpretação deve integrar o conhecimento multidisciplinar proporcionado pelas diversas abordagens geofísicas.

Deve-se realizar esforços para a criação de consórcios e de cooperação de pesquisas entre a área acadêmica, entidades do governo e empresas, para a realização de levantamentos, processamentos e interpretações dos dados a exemplo do que ocorre em outros países de dimensões continentais.

Devido às dificuldades de acesso, são recomendados como prioritários os levantamentos através de plataformas aéreas (aerogravimetria e aeromagnetometria), o aproveitamento dos rios navegáveis (sísmica e gravimetria fluvial), a instalação de redes de equipamentos para a coleta de dados de suporte (rede gravimétrica fundamental, estações de Maré Solida) e estudos regionais (tomografia telessísmica; sondagens geomagnéticas profundas, paleomagnetismo).

Empresas de mineração devem disponibilizar coleções de amostras catalogadas, para o inicio dos estudos de caracterização das propriedades físicas de rochas e minérios, tais como as magnéticas, elétricas, elásticas, térmicas, radioativas, de densidade e permeabilidade; Devem também dar apoio logístico em levantamentos próximos às suas áreas de atuação. 
Os levantamentos de geofisica profunda devem ser ajustados ao Programa de Levantamentos Aerogeofísicos na Amazônia (PLAA). Estes dados e os de outros programas geofisicos executados por entidades públicas, empresas e universidades devem se tornar públicos em curto prazo após serem adquiridos.

Deve-se melhorar substancialmente a capacidade de pessoal e equipamentos especializados para levantamentos geofísicos profundos na área acadêmica, instituições governamentais e empresas, principalmente aquelas que atuam na Amazônia; mobilizar pesquisadores para atuarem em pesquisa na Amazônia e viabilizar recursos para trabalhos de campo, contratação de pessoal técnico especializado e para manutenção de equipamentos.

Deve-se obter apoio financeiro para viabilizar seminários anuais de discussões e avaliações do andamento e dos resultados dos projetos da Amazônia e elaborar mapas ilustrativos da situação atual do conhecimento e do que vai ser adquirido através dos projetos, e divulgá-los em publicações impressas e via internet.

\section{DETALHAMENTO DAS PROPOSTAS}

Os programas e projetos de geofísica profunda propostos pelo Comitê têm como objetivo comum a definição dos grandes domínios da crosta e do manto superior no Cráton Amazônico (incluindo escudos antigos e bacias sedimentares). A seguir, os projetos estão agrupados de acordo com o método geofísico a ser utilizado, a saber: Campos Potenciais (Gravimetria \& Magnetometria), Indução Eletromagnética, Sísmica \& Sismologia, Paleomagnetismo \& Petrofísica, e Programa de Capacitação Nacional Especializada.

\section{Campos Potenciais}

Dados terrestres e aerotransportados de gravimetria e magnetometria podem ser filtrados para separar os comprimentos de onda longos e médios necessários em modelos das anomalias do campo que refletem condições a grandes profundidades. Estes dados podem ser comparados aos mapas de campo potencial derivados de satélites, necessitando porém um bom controle independente da espessura da crosta. No caso da gravimetria, especificamente, as anomalias encontradas nos modelos refletem as variações de densidade na crosta e manto superior, associadas às grandes estruturas e condições térmicas.

\section{Métodos Gravimétricos}

\section{Projeto de Levantamentos Aerogravimétricos em Transectas Regionais}

Considerando-se, por um lado, a enorme dificuldade de acesso por via terrestre aos vastos interflúvios na região da floresta Amazônica, e por outra, a rapidez, homogeneidade, baixo custo relativo e elevada qualidade da informação obtida pela aerogravimetria, graças aos aprimoramentos do método, sugere-se o seu uso extensivo e prioritário, tanto nas regiões de escudos antigos como nas bacias sedimentares da Amazônia.

Neste sentido, são propostos levantamentos aerogravimétricos em 24 perfis com $1.400 \mathrm{~km}$ cada, com orientação NS cortando toda a região Amazônica (escudos e bacias), com espaçamento de $100 \mathrm{~km}$, e duas seções de $2.400 \mathrm{~km}$ cada, orientadas EW; num total de $38.400 \mathrm{~km}$ lineares. Inclui a parte de interpretação dos dados por consultores especializados, com elaboração de seções e mapas identificando a estruturação da crosta e sua compartimentação em blocos maiores que 100 x 100 km; a elaboração de texto explicativo em papel e em meio magnético (CD-ROM) e a re-interpretação e integração de outros dados.

Base de cálculo: US $\$ 80,00 / \mathrm{km}$, inclusive com o levantamento gravimétrico;

Estimativa de Custo: US\$3.072.000,00

Prováveis Fontes de Recursos: ANP, SGB (CPRM), $\mathrm{CNPq}$ /MCT e FAPESP.

Execução: Levantamentos: Companhias prestadoras de serviços aerogeofísicos; consultores, sob contrato e a SGB (CPRM);

Processamentos e interpretações: IAG/USP, UFPA, ON, UFRN, UFC, UFPR e SGB (CPRM). 


\section{Projeto Ampliação da Rede Gravimétrica} Fundamental na Amazônia

A rede gravimétrica fundamental de responsabilidade do Observatório Nacional - ON possui, na Amazônia, apenas 10 estações gravimétricas e, assim mesmo, com locações muito mal distribuídas. Este número é de todo insuficiente para permitir um mínimo de amarração e controle dos levantamentos gravimétricos que estão e deverão ser executados na Amazônia.

Esta proposta sugere a implantação de pelo menos 40 novas estações gravimétricas na região amazônica, em duas etapas, de forma a que se obtenha uma rede de estações homogeneamente distribuídas, tanto nos escudos como nas bacias; capaz de permitir a devida amarração e calibração dos levantamentos aerogravimétricos e gravimétricos fluviais ou terrestres.

Base de cálculo: U\$2.875,00 /estação para custeio de deslocamentos;

Estimativa de Custo: US\$ 115.000,00;

Possíveis Fontes de Recursos: CNPq/MCT, ANP, FAPESP

Execução: ON/MCT.

\section{Projeto Compilação \& Interpretação de Dados Gravimétricos Já Existentes}

Como já existem na Amazônia alguns levantamentos gravimétricos localizados e dispersos, executados por diferentes empresas (PETROBRÁS, DOCEGEO, SOPEMI, etc.) e instituições de pesquisa (ON, IAG-USP, e outras), torna-se necessário conhecer e fazer bom uso da informação já existente. Para tanto, torna-se necessário um projeto que faça o levantamento, controle de qualidade, amarração à Rede Gravimétrica Fundamental, processamento dos dados, e geração de mapas de anomalias e de CD-ROM contendo todos os dados pontuais terrestres e de aerogravimetria do Alto Tapajós e Alto Xingú. O projeto contempla a compilação de dados de todas as fontes disponíveis, incluindo: ANP/PETROBRÁS, SGB(CPRM), ON, DOCEGEO/CVRD, SOPEMI, etc. e o processamento e interpretação visando a obtenção de informações profundas.

Previsão de Recursos: US\$34.500,00

Possíveis Fontes de Recursos: ANP; SGB (CPRM); CNPq; FAPESP.

Possíveis Executores: ON/MCT, IAG/USP,UFPR, UFC, UFRN; SGB (CPRM).

4. Projeto Perfis Gravimétricos Fluviais

Valendo-se da oportunidade da realização dos perfis sísmicos fluviais, propostos para serem realizados no âmbito de outro projeto, e considerandose que o aumento de custo é insignificante, propõese a realização de levantamento gravimétrico ao longo dos rios navegáveis da Bacia Amazônica, tendo como eixo o Rio Amazonas. Como subproduto dos levantamentos de sísmica fluvial aqui propostos, será utilizado o mesmo navio para os levantamentos geofísicos. O trabalho inclui o processamento e interpretação dos dados obtidos, visando a caracterização de estruturas profundas.

Estimativa de Custo: custo embutido no projeto de sísmicafluvial;

Possíveis Fontes de Recursos: ANP; SGB(CPRM); FAPESP; CNPq;

Execução: levantamentos: Empresa prestadora de serviço de levantamento geofísico fluvial, sob contrato; Processamentos e interpretações: IAG/USP; UFRN; UFPR, UFC, ON;

\section{Métodos Magnetométricos}

\section{Projeto Interpretação de Dados Aeromagnéticos para Geofísica Profunda}

Com base no tratamento de dados de levantamentos aeromagnéticos existentes e em execução em toda a Amazônia (bacias e escudos), deve-se realizar análises e interpretações de dados filtrados de longo e médio comprimento de onda, visando a identificação e definição de estruturas de grande porte na crosta e no manto superior.

Estimativa de Custo: US\$ 95.000,00 
Possíveis Fontes de Recursos: MCT, ANP e SMM/ MME.

Possíveis Executores: UnB, IAG, UFPA, UFPR, UFRN, UFC, CENPES/PETROBRAS

\section{Indução Eletromagnética}

Estudos de Indução Eletromagnética para a obtenção de parâmetros de condutividade elétrica em profundidades litosféricas baseiam-se na detecção de camadas condutoras, através das correntes elétricas induzidas pelo campo geomagnético externo. Nestas profundidades, a condução é facilitada pelo início da fusão parcial dos minerais, geralmente associada à composição das rochas, conteúdo de material metassomático, pressão e temperatura, o que fornece ao método a sensibilidade para definir províncias tectônicas, pela variação da condutância e de anisotropia, e pela detecção da base da litosfera térmica. Dois métodos têm sido amplamente utilizados: Rede de Sondagens Geomagnéticas (GDS: Geomagnetic Deep Soundings) e Sondagens Magnetotelúricas (MT). O primeiro utiliza um grande número de magnetômetros distribuídos em uma malha para a coleta simultânea das variações do campo geomagnético, na definição regional dos extensos condutores e o segundo para a definição em detalhe, principalmente da profundidade, das variações de condutância e anisotropia eletromagnética.

\section{Projeto Perfis de Sondagens Magnetotelúricas (MT)}

Considerando a existência de equipamentos modernos e de capacitação de pessoal em institutos de pesquisa e universidades brasileiras em métodos magnetotelúricos, bem como o baixo custo da obtenção de dados com esta metodologia, sugerese, para o conhecimento dos grandes traços das estruturas litosféricas, a realização de perfis de sondagens magnetotelúricas (MT) com aproximadamente 800 estações com espaçamento de $10 \mathrm{~km}$, ao longo de $8.000 \mathrm{~km}$ de estradas e rios, em áreas de escudos antigos do Cráton Amazônico, seguido do processamento dos dados e interpretação dos resultados visando detectar descontinuidades e estruturas profundas. O projeto deve ser executado ao longo de 8 anos, ou seja, com coleta de 100 estações por ano, principalmente no período de estiagem, utilizando-se dez sistemas MT, tendo início pela Faixa Maroni/Itacaiunas (Pará e Amapá).

Base de cálculo: US\$1.575,00/sondagem, incluindo coleta, processamento, interpretação de dados, produção de mapas de inversões 2-D, e contratação de pessoal adicional e/ou serviços).

Estimativa de Custos: US\$1.260.000,00

Possíveis Fontes de Recursos: CNPq/MCT, ANP, FAPESP e empresas (SOPEMI, DOCEGEO, RTZ e outras).

Exeсuс̧ão: ON/MCT, INPE/MCT, UFPA.

\section{Projeto Rede de Sondagens Geomagnéticas} (GDS)

Utilizando-se apenas do registro do campo geomagnético, estabelecer um total de 10 arranjos com redes compostas por 30 estações de sondagens geomagnéticas coletando dados simultâneos durante 4-6 meses, com espaçamentos da ordem de $100 \mathrm{~km}$ entre estações, em toda a área de escudos antigos da Amazônia (cerca de $2.500 .000 \mathrm{~km}^{2}$ ).

Para tanto, executar 2 arranjos de 500 x 500 $\mathrm{km}$ cada ano, concluindo o projeto em 5 anos, com um total de 300 sondagens. Para viabilizar este projeto necessita-se de convênio/acordo internacional para obtenção, por empréstimo, de 30 magnetômetros. Uma das possibilidades é através da Flinders University-Adelaide/Austrália. Alternativamente, pode-se construir unidades GDS no Brasil ao custo de US\$ 9.000,00/unidade.

Base de cálculo: US\$ 1.300,00/sondagem e U\$ 52.000,00 para serviços de importação, reparo, calibrações e baterias das unidades GDS;

Estimativa de Custo: US\$ 442,000.00

Possíveis Fontes de Recursos: MCT, ANP, empresas.

Execução: ON/MCT, INPE/MCT, UFPA.

\section{Sísmica \& Sismologia}

Estudos de propagação de ondas elásticas têm sido amplamente utilizados para a obtenção de 
informações litosféricas. Para a penetração na crosta utilizam-se métodos ativos de sísmica de reflexão com o devido registro de longos períodos, maiores espaçamentos de geofones e entre detonações, e cargas com força acima de 50 ton. Na sismologia, registram-se os sinais oriundos dos terremotos por sistemas de banda larga e multi-componentes. Diversos métodos de análise são geralmente empregados. Modelos tomográficos de velocidades de ondas P \& S são utilizados em estudos da litosfera através da análise das alterações na velocidade da onda. Análises de Função do Receptor ("Receiver Functions") podem determinar distintas mudanças na estrutura da velocidade das ondas $\mathrm{S}$, e observações de separação de ondas $\mathrm{S}$ identificam as anisotropias elásticas que poderiam estar associadas a tendências estruturais. Descontinuidades nas propriedades elásticas têm sido correlacionadas a importantes variações na composição e fases petrográficas em distintas camadas litosféricas.

\section{Sísmica}

\section{Projeto Sísmica Fluvial}

A sísmica de reflexão constitui-se no método de maior definição para estudos da estrutura da crosta e também da estratigrafia/estrutura das bacias sedimentares. Seu alto custo inibe a aplicação do método nas áreas de escudo, porém nem tanto nas bacias sedimentares e para a indústria petrolífera.

Em vista do exposto, sugere-se a perfilagem sísmica profunda, com utilização de navio geofísico de pequeno porte, ao longo de todo o percurso navegável dos rios da bacia hidrográfica do Amazonas no território brasileiro, num total de $8.000 \mathrm{~km}$ lineares. Registro sísmico com tempo máximo permitido acima de $20 \mathrm{~s}$, espaçamento entre tiros de 50 metros e carga com força acima de 50 ton, de forma a obter, tanto o detalhamento estratigráfico/estrutural das bacias sedimentares como a definição da estrutura profunda na crosta/manto superior abaixo e nas bordas das bacias. Incluir na perfilagem, como subproduto, também registros gravimétricos e magnetométricos. Processamento dos dados sísmicos, gravimétricos e magnéticos.
Base de cálculo: perfilagem a US\$ 525,00 / km e US\$ $100.000,00$ para processamentos e interpretações;

Estimativa de Custo: US\$ 4.300.000.00;

Possível Fonte de Recursos: ANP

Execução: Perfilagens e processamentos: Empresa de serviços de geofísica fluvial/marinha, sob contrato. Interpretações: PETROBRAS, universidades.

\section{Sismologia}

\section{Projeto Tomografia Regional com Ondas de Superficie}

Elaboração da tomografia da crosta/manto superior com emprego de ondas elásticas de superfície, de toda a região Amazônica (bacias sedimentares e escudos antigos), visando a identificação de extensas estruturas litosféricas, através de uma rede de 16 estações (fixas e móveis) homogeneamente distribuídas. Registro de dados por um período de dois anos e interpretação dos dados. Seriam usadas quatro estações instaladas em cooperação com a Eletronorte e três estações da rede mundial. Para viabilização do projeto há necessidade da aquisição e implantação de nove novas estações e estabelecimento de uma central de armazenamento, processamento, controle de qualidade e gerenciamento de dados. Aproveitando-se dessa infra-estrutura, seriam instaladas oito estações de Maré Sólida para estudos da espessura elástica da litosfera. Em cada estação, registram-se dados por um período mínimo de seis meses e efetuam-se visitas mensais para o recolhimento dos dados.

Base de cálculo: US\$ 36.000,00 /aquisição novas estações; custeio mensal de cada estação, incluindo consumo e mão de obra de três técnicos US\$ 1.630,00 / mês/estação; Instalação de estações de Maré: US\$ 5.000,00 /estação

Estimativa de Custo: US\$ 990,000.00

Possíveis Fontes de Recursos: MCT, ANP, FAPESP.

Possíveis Executores: IAG/USP, UnB.

10. Projeto Tomografia de Ondas Telessísmicas $(P$ e $S)$ 
Estabelecimento de rede de 30 estações móveis, por período de dois anos na região dos rios Xingu e Iriri (200 x $500 \mathrm{~km})$, objetivando a definição de anisotropias e estruturas maiores da litosfera. Viabilização do projeto através de convênios de cooperação com instituições no exterior (Carnegie Institution-EUA, ETH-Suiça, Potsdam-Alemanha, e outras).

Base de cálculo: US\$ 760,00 /mês /estação para custeio de instalação, manutenção e mão de obra (um pesquisador e um técnico); US\$ 52.800,00 para importação e manutenção das unidades.

Estimativa de Custos: US\$ 600,000.00

Possíveis Fontes de Recursos: CNPq/MCT, FAPESP e empresas.

Executores: IAG/USP, UnB.

\section{Paleomagnetismo e Petrofísica}

\section{Projeto Evolução Tectônica dos Blocos} Cratônicos da Amazônia por Paleomagnetismo

Determinação, através da caracterização das direções paleomagnéticas, das translações e rotações (separações e colisões) dos blocos que formam a atual região Amazônica, desde o Paleoproterozóico Mesoproterozóico e a identificação das zonas de suturas das colisões continentais proterozóicas. Inclui estudos do magnetismo das rochas, estratigrafia magnética e os parâmetros magnéticos (susceptibilidade, anisotropia, polaridade, coersividade, temperatura de Curie) Identificação das zonas de suturas das colisões continentais proterozóicas.

Base de cálculo: Trabalhos de campo para coleta de amostras, de aproximadamente 10 semanas, por US\$ 4.600,00/semana incluindo diárias e transporte.

Estimativa de Custo: US\$ 46,000.00.

Possíveis Fontes de Recursos: CNPq, FAPESP. Exeсис̧ão: IAG/USP.

\section{Projeto Banco de Dados Petrofísicos}

Implantação de um banco de dados petrofísico de rochas e minérios, com as principais propriedades físicas características das amostras, entre elas: as magnéticas, elásticas, densidade, radioativas, porosidade, permeabilidade, condutividade elétrica e térmica, etc. Coleta sistemática de amostras e determinação das propriedades, por um período inicial de 24 meses, incluindo a compilação de dados de literatura, novas determinações e estudos de correlações.

Base de cálculo: Despesas com transporte e preparação de aproximadamente mil amostras e determinações ao custo de US\$ 958,00 / mês;

Estimativa de Custos: US\$23,000.00

Possíveis Fontes de Recursos: CNPq, FAPESP. Execução: IAG/USP.

\section{Programa De Capacitação Nacional}

\section{Formação Clássica}

\section{Projeto Formação de Doutores}

Formação de 16 doutores especialistas em subáreas, através da elaboração de teses associadas aos projetos anteriormente propostos, permitindo ao mesmo tempo suas viabilizações no prazo de quatro anos.

Para atrair candidatos e tornar exequiível a formação de doutores especialistas na área e sobre os projetos propostos, é fundamental que seja criado, no âmbito do MCT, um pacote de bolsas de doutoramento com valores diferenciados, e reserva técnica, a exemplo e ao nível dos programas da ANP e da FAPESP.

\section{Base de cálculo: custo por ano US\$ 11.656,00 / aluno}

Estimativa de Custos: US\$ 746,000.00

Possíveis Fontes de Recursos: MCT, ANP, FAPES. Execução: Universidades e Institutos de Pesquisa com Pós-Graduação .

\section{Formação Continuada}

\section{Projeto de Cursos de Curta Duração}

Cursos de curta duração (até 15 dias) em temáticas específicas da geofísica profunda, destinados ao aperfeiçoamento contínuo de 
profissionais, a serem oferecidos por especialistas do mais alto nível internacional. Dois cursos por ano nos próximos oito anos.

Base de cálculo: US\$12.000,00/curso, incluindo despesas de transporte e diárias do corpo docente; Estimativa de Custos: US\$ 192,000.00.

Possiveis Fontes de Recursos: MCT, ANP, SMM/ CPRM.

Execução: ADIMB, IAG/USP, UnB, INPE, ON, UFPR, UFC, UFRN, UFBA,UFPA.

\section{Projeto de Formação Continuada de Pessoal "on the job"}

Capacitação e especialização de profissionais através da alocação temporária de consultores especialistas em alguns dos projetos anteriormente descritos, principalmente nas fases de implantação, tratamento e interpretação de dados. Prevê-se oito consultores (pesquisadores visitantes) por um período máximo de dois anos cada.

Base de cálculo: US\$ 7.400,00 / consultor / mês, incluindo passagens, para um total de 50 meses;

Estimativa de Custos: US\$ 370,000.00

Possiveis Fontes de Recursos: MCT, ANP, CNPq, FAPESP;

Execução: Empresas de mineração, universidades, ADIMB.

\section{PRIORIZAÇÃO \\ E OUTRAS RECOMENDAÇÕES}

Sugerem-se três fases na priorização para programas/projetos propostos, com base essencialmente em uma sequiência estratégica para que se possa atingir o objetivo maior da Plataforma:

\section{$1^{a}$ Prioridade - $1^{a}$ Fase: 2000-2001}

$\S$ Levantamentos Aerogravimétricos em Transectas Regionais (completo).

$\S$ Ampliação da Rede Gravimétrica Fundamental $\left(1^{\mathrm{a} e t a p a}=50 \%\right)$.

$\S$ Sísmica Fluvial e Gravimetria Fluvial (completo).
$\S \quad$ Rede Regional de Sondagens Geomagnéticas $\left(1^{\mathrm{a}}\right.$ etapa $\left.=20 \%\right)$.

$\S$ Perfis de Sondagens Magnetotelúricas ( $1^{\mathrm{a}}$ etapa $=20 \%$ ).

$\S$ Formação de Doutores $\left(1^{\mathrm{a}}\right.$ etapa $\left.=12,5 \%\right)$.

$\S$ Cursos de Curta Duração ( $1^{\mathrm{a}}$ etapa $\left.=12,5 \%\right)$.

$\S$ Formação Continuada de Pessoal ( $1^{\mathrm{a}}$ etapa $=12,5 \%)$.

\section{$2^{a}$ Prioridade - $2^{a}$ Fase - 2001-2004}

$\S$ Interpretação de Dados Aeromagnéticos para Geofísica Profunda (60\%);

§ Ampliação da Rede Gravimétrica Fundamental $\left(2^{a}\right.$ etapa $\left.=50 \%\right)$

$\S$ Compilação de Dados Gravimétricos Já Existentes $\left(1^{\text {a }}\right.$ etapa $\left.=70 \%\right)$.

$\S$ Rede Regional de Sondagens Geomagnéticas $\left(2^{\mathrm{a}}\right.$ etapa $\left.=50 \%\right)$.

$\S \quad$ Perfis de Sondagens Magnetotelúricas ( $2^{\mathrm{a}}$ etapa $=50 \%$ ).

$\S \quad$ Tomografia Regional de Ondas de Superfície (completo).

$\S$ Tomografia Telessísmicas $\left(1^{\mathrm{a}}\right.$ etapa $\left.=70 \%\right)$.

§ Evolução Tectônica dos Blocos Cratônicos da Amazônia por Paleomagnetismo (completo).

$\S$ Banco de Dados Petrofísicos ( $1^{a}$ etapa $=$ $60 \%$ ).

$\S$ Formação de Doutores $\left(2^{\mathrm{a}}\right.$ etapa $\left.=37,5 \%\right)$.

$\S$ Cursos de Curta Duração ( $2^{\mathrm{a}}$ etapa $=75 \%$ ).

$\S$ Formação Continuada de Pessoal ( $2^{\mathrm{a}}$ etapa $=75 \%$ ).

\section{$3^{a}$ Prioridade - $3^{a}$ Fase: $2005-2008$}

$\S$ Compilação de Dados Gravimétricos (2a etapa $=30 \%$ ).

$\S$ Tomografia Telessísmicas ( $3^{\mathrm{a}}$ etapa $\left.=30 \%\right)$.

$\S$ Rede Regional de Sondagens Geomagnéticas $\left(3^{\mathrm{a}}\right.$ etapa $\left.=30 \%\right)$.

$\S \quad$ Perfis de Sondagens Magnetotelúricas ( $3^{\mathrm{a}}$ etapa $=30 \%$ ).

$\S$ Interpretação Dados Aeromagnéticos Geofísica Profunda $\left(2^{\circ}\right.$ etapa $\left.=40 \%\right)$.

$\S$ Formação de Doutores ( $3^{\mathrm{a}}$ etapa $\left.=50 \%\right)$. 
$\S$ Cursos de Curta Duração ( $3^{\mathrm{a}}$ etapa $\left.=12,5 \%\right)$.

$\S$ Formação Continuada de Pessoal ( $3^{\mathrm{a}}$ etapa $=12,5 \%$ );

$\S$ Banco de dados petrofísicos $\left(2^{\mathrm{a}}\right.$ etapa $=$ $40 \%)$

\section{Outras Recomendações}

\section{Ao MCT/Fundo Setorial de Mineração/CNPq}

$\S$ Viabilizar bolsas especiais para doutorado e para pesquisador, nos níveis e moldes da ANP e da FAPESP, especificamente para a Plataforma.

\section{Ao MCT}

$\S$ Destinar, através do PPA - Ação Amazônica, recursos ao ON e INPE, que permitam a viabilização dos projetos aqui propostos para serem executados pelos referidos centros de pesquisa.

3. Às Instituições Patrocinadoras

$\S \quad$ Exigir e embutir recursos para avaliações dos resultados parciais e finais das pesquisas em seminários internos dos projetos da Plataforma EXMIN/Amazônia, a exemplo dos seminários organizados pelo PADCT/ GTM.

\section{Ao Serviço Geológico do Brasil}

$\S$ Criar no âmbito da Divisão de Geologia capacitação em pessoal e equipamentos para realizar estudos de geofísica profunda, a exemplo dos demais serviços geológicos.

\section{5. Às Empresas de Exploração Mineral}

$\S$ Disponibilizar dados geofísicos (magnéticos, gravimétricos e sísmicos) em rede aberta, para auxiliar nas interpretações de estruturas profundas.

\section{Ao Comitê de Janelas Estratégicas}

$\S \quad$ Incluir a caracterização das propriedades petrofísicas de rochas e minérios no estudo de detalhe de janelas estratégicas centradas em depósitos minerais.

\section{Ao Comitê de Integração}

$\S \quad$ Elaborar mapas comparativos Amazônia x Austrália mostrando as densidades relativas das informações, com relação aos conhecimentos geofísicos, geológicos e geoquímicos.

$\S$ No interesse da Geofísica Profunda, sugerese que sejam priorizados, tanto nas regiões de escudos como de bacias, os levantamentos aerogeofísicos das regiões ainda sem cobertura até o momento, inclusive durante a execução do Programa Aerogeofísico da Amazônia (CPRM-2000). A respeito desse programa, considera-se ser suficiente, nas regiões de borda das bacias sedimentares, levantamentos aerogeofísicos com espaçamentos entre linhas de 1000 metros.

\section{Aos Grupos de Pesquisa Acadêmica}

- Avançar nos estudos de topografia dinâmica a partir de modelos de soerguimentos e processos de erosão, com dados de traço de fissão em apatitas;

- Determinações de geotermas litosféricas estabelecidas em estudos petroquímicos de materiais de xenólitos e determinações de fluxo de calor na superfície;

Elaboração de mapas 3-D com estimativas das estruturas litosféricas a partir dos diversos parâmetros geofísicos a serem obtidos pelo Programa, complementados por outros dados como os de maré sólida, fluxo geotérmico, etc. 